\title{
Longitudinal association between physical activity and health-related quality of life among community-dwelling older adults: a longitudinal study of Urban Health Centres Europe (UHCE)
}

Xuxi Zhang ${ }^{1,2}$, Siok Swan Tan', Carmen Betsy Franse1, Tamara Alhambra-Borrás ${ }^{3}$, Arpana Verma ${ }^{4}$, Greg Williams ${ }^{4}$, Amy van Grieken ${ }^{1}$ and Hein Raat ${ }^{1 *}$

\begin{abstract}
Background: Physical activity (PA) may play a key role in healthy aging and thus in promoting health-related quality of life (HRQoL). However, longitudinal studies on the association between PA and HRQoL are still scarce and have shown inconsistent results. In this study, we aimed to examine the longitudinal association between frequency of moderate PA and physical and mental HRQoL. Secondly, to assess the association between a 12-month change in frequency of moderate PA and HRQoL.

Methods: A 12-month longitudinal study was conducted in Spain, Greece, Croatia, the Netherlands, and the United Kingdom with 1614 participants (61.0\% female; mean age $=79.8 ; \mathrm{SD}=5.2)$ included in the analyses. Two categories of the self-reported frequency of moderate PA including 1) 'regular frequency' and 2) 'low frequency' were classified, and four categories of the change in frequency of moderate PA between baseline and follow-up including 1) 'continued regular frequency', 2) 'decreased frequency', 3) 'continued low frequency' and 4) 'increased frequency' were identified. Physical and mental HRQoL were assessed by the 12-Item Short-Form Health Survey (SF-12).

Results: The frequency of moderate PA at baseline was positively associated with HRQoL at follow-up. Participants with a continued regular frequency had the highest HRQOL at baseline and follow-up. Participants who increased the frequency of moderate PA from low to regular had better physical and mental HRQOL at follow-up than themselves at baseline. After controlling for baseline HRQOL and covariates, compared with participants who continued a regular frequency, participants who decreased their frequency had significantly lower physical $(B=-4.42 ; P<.001)$ and mental $(B=-3.95 ; P<.001) H R Q O L$ at follow-up; participants who continued a low frequency also had significantly lower physical $(B=-5.45 ; P<.001)$ and mental $(B=-4.10 ; P<.001)$ HRQoL at follow-up. The follow-up HRQoL of participants who increased their frequency was similar to those who continued a regular frequency.
\end{abstract}

\footnotetext{
* Correspondence: h.raat@erasmusmc.nl

'Department of Public Health, Erasmus University Medical Center, P.O. Box 2040, 3000, CA, Rotterdam, The Netherlands

Full list of author information is available at the end of the article
}

\section{$\triangle B M C$}

C C The Author(s). 2021 Open Access This article is licensed under a Creative Commons Attribution 4.0 International License, which permits use, sharing, adaptation, distribution and reproduction in any medium or format, as long as you give appropriate credit to the original author(s) and the source, provide a link to the Creative Commons licence, and indicate if changes were made. The images or other third party material in this article are included in the article's Creative Commons licence, unless indicated otherwise in a credit line to the material. If material is not included in the article's Creative Commons licence and your intended use is not permitted by statutory regulation or exceeds the permitted use, you will need to obtain permission directly from the copyright holder. To view a copy of this licence, visit http://creativecommons.org/licenses/by/4.0/ The Creative Commons Public Domain Dedication waiver (http://creativecommons.org/publicdomain/zero/1.0/) applies to the data made available in this article, unless otherwise stated in a credit line to the data. 
Conclusions: Maintaining or increasing to a regular frequency of PA are associated with maintaining or improving physical and mental HRQoL. Our findings support the development of health promotion and long-term care strategies to encourage older adults to maintain a regular frequency of PA to promote their HRQoL.

Keywords: Physical activity (PA), Longitudinal study, Health-related quality of life (HRQoL), Physical HRQoL, Mental HRQoL, Older adults

\section{Background}

Health-related quality of life (HRQoL) is a multidimensional construct that specifically focuses on health-related aspects of well-being and reflects the subjective perception of the impact of physical and mental functioning on a person's daily living [1]. HRQoL is an important component in determining the health status of older adults during the aging process [2]. Population aging is associated with increased morbidity and institutionalization, which may adversely affect the HRQoL among older adults [3]. Physical activity (PA) may play a key role in healthy aging and thus in promoting HRQoL [2]. A better understanding of the association between PA and HRQoL among older adults might help policy makers to develop more precise policies for long-term care and healthy aging [4].

Previous cross-sectional studies have shown consistent positive associations between PA and HRQoL [5, 6]. However, longitudinal studies on the association between PA and HRQoL are still scarce and have shown inconsistent results $[6,7]$. Some longitudinal studies reported that PA was positively associated with better physical and mental HRQoL $[8,9]$. Conversely, some studies reported PA was not associated with improved physical or mental HRQoL [10, 11]. In addition, few studies focused on the longitudinal association between change in PA and HRQoL, [12] which is an important scientific evidence for the development of health promotion and long-term care strategies. Furthermore, studies on the association between PA and HRQoL among older adults, especially people aged over 70 , are relatively limited [2]. More studies are needed to have a better understanding of the longitudinal association between PA and HRQoL in older populations.

Therefore, the aim of our study is to examine the longitudinal association between frequency of moderate PA and physical and mental HRQoL among communitydwelling older adults aged over 70. Secondly, we assessed the association between a 12-month change in frequency of moderate PA and HRQoL.

\section{Methods}

\section{Participants}

The Urban Health Centres Europe (UHCE) project aimed to promote the healthy aging of older adults using integrated care pathways in community settings at study sites in five European countries, including Spain, Greece,
Croatia, the Netherlands, and the United Kingdom [1315]. At each study site, older adults over age 70 , who lived independently and were expected to be able to participate in the study for at least 6 months were invited to participate. A total of 2325 participants were recruited between May 2015 and June 2017, of which 1215 received integrated care pathways (intervention) and 1110 were enrolled in the control group. At the 12-month follow-up, 986 in the intervention group (81.2\%) and 858 in the control group (77.3\%) completed the questionnaire [13]. Participants in the intervention group received care following the UHCE approach which comprised of three elements: 1) risk assessment, 2) shared-decision making and 3) referral to care pathways aimed at reducing fall risk, inappropriate medication use, loneliness or frailty by specific interventions [13]. Persons in the control group received their usual care [13]. Further details on these interventions are described elsewhere [13, 14]. Data were obtained from selfreported questionnaires at baseline and 12 months of follow-up. Ethics committee procedures were followed at all study sites and approval was provided [13, 14]. Written informed consent was obtained from all participants [13]. The study was registered in the ISRCTN registry as ISRCTN52788952.

The current study included participants in the UHCE project who had completed both baseline and follow-up questionnaires $(n=1844)$ [13]. We excluded participants with missing data on PA $(n=71)$ or HRQoL $(n=121)$ or Age $(\mathrm{n}=1)$. Additionally, participants whose age $<70$ years $(n=37)$ were excluded. Thus, a total of 1614 participants were included in the analyses of the current study.

Compared with the study population $(n=1614)$, the participants excluded from the study $(n=230)$ were younger $(P<.001)$ and had less often completed secondary or higher education $(P<.001$; details on how to define 'secondary or higher education' can be found in the following section). No significant differences in sex, living situation, smoking, alcohol risk, frailty, and multimorbidity between these two groups were found.

\section{Measurements}

\section{Physical activity (PA)}

The frequency of moderate PA was measured using one question from the Frailty Instrument of the Survey of Health, Aging and Retirement in Europe (SHARE-FI): 
"How often do you engage in activities that require a low or moderate level of energy such as gardening, cleaning the car, or taking a walk?". Answer categories included (a) more than once a week, (b) once a week, (c) one to three times a month and (d) hardly ever, or never. If the answer falls into the frequency of "more than once a week", it would be considered as 'Regular frequency' (more than once a week). If the answer was "once a week", "one to three times a month", or "hardly ever, or never", it would be taken as 'Low frequency' (once a week or less). In addition, the change in the frequency between baseline and follow-up was grouped into four categories: (1) 'Continued regular frequency' (more than once a week), (2) 'Decreased frequency' (from regular to low frequency), (3) 'Continued low frequency' (once a week or less) and (4) 'Increased frequency' (from low to regular frequency) [16].

\section{Health-related quality of life (HRQoL)}

Physical and mental HRQoL were measured by the SF12 . It is a widely used patient-reported survey for measuring HRQoL which consists of 12 questions covering eight health domains, including general health, mental health, vitality, social functioning, role limitation due to physical health problems, role limitation due to emotional problems, bodily pain limiting usual activities, and physical functioning [17]. The eight domains of SF-12 can be summarized in the Physical Component Summary (PCS; physical HRQoL) and Mental Component Summary (MCS; mental HRQoL), both ranging from 0 (lowest) to 100 (highest level of health) [17, 18]. A 3unit change or more in PCS and MCS are considered clinically important changes [19].

\section{Covariates}

We assessed covariates including age (in years), sex, country, educational level, living situation, smoking, alcohol risk, frailty, and multi-morbidity at baseline. Educational level concerned the highest level of education completed by the participant. It was categorized according to the 2011 International Standard Classification of Education (ISCED) into primary or less (ISCED 0-1), secondary or equivalent (ISCED 2-5), and tertiary or higher (ISCED 6-8) [20]. The living situation was categorized as 'not living with others' or 'living with others' (a partner, child (ren) and/or others). Smoking was measured with one item that assessed whether a person currently smoked. Alcohol risk was measured with the AUDIT-C, [21] which is a 3-item screener to grade high-risk alcohol use on a scale from 0 (lowest risk) to 12 (highest risk). A score of at least 4 for men and 3 for women was regarded as hazardous drinking or active alcohol use disorder [21]. Frailty was measured with the Tilburg Frailty Indicator (TFI), which is a reliable and validated instrument to identify frailty in communitydwelling older adults [22]. An overall frailty score can be determined by adding up the 15 items (score range 0 15 ), and participants with a total score of at least five were diagnosed as being frail [23]. Multi-morbidity was defined as having at least two of the following 14 chronic conditions [24]: heart attack, hypertension, diabetes, stroke, high blood cholesterol, asthma, arthritis, osteoporosis, chronic lung disease, cancer or malignant tumor, stomach or duodenal ulcer, Parkinson's disease, cataract and hip fracture or femoral fracture [25].

\section{Statistical analysis}

To examine mean differences in PCS and MCS scores between groups, effect sizes were estimated by calculating the mean difference between two subgroups, and then dividing the result by the pooled standard deviation. Cohen's effect sizes (d) were used for the interpretation of relevant differences: $0.20 \leq \mathrm{d}<0.50$ was considered a small difference; $0.50 \leq \mathrm{d}<0.80$ was considered a moderate difference; $\mathrm{d} \geq 0.80$ was considered a large difference [26].

The longitudinal association between frequency of moderate PA and HRQoL was estimated with multivariate linear regression models. Two separate regression models were built for physical and mental HRQoL at 12 months of follow-up as the dependent variable, and frequency of moderate PA at baseline as the independent variable. The first set of models were adjusted for HRQoL at baseline and country (crude model). The second set of models were additionally adjusted for age, sex, educational level, living situation, smoking, alcohol risk, frailty, and multi-morbidity (adjusted model) [16]. Since the UHCE project was an intervention study, and participants were divided over an intervention and a control group, intervention condition (yes/no) was also added to the adjusted model as a covariate [16].

The association between the 12-month change in frequency of moderate PA and physical or mental HRQoL was assessed using the same crude and adjusted multivariate linear regression models as described above, taking the change in frequency of moderate PA as the independent variable [16].

Furthermore, interactions between baseline frequency of moderate PA or 12-month change in frequency of moderate PA and age, sex, country, educational level, living situation and intervention condition (yes/no) on HRQoL were assessed with UNIANOVA [16]. Bonferroni correction was applied for multiple testing ( $P=$ $0.05 / 24=0.002$ ). Apart from an interaction between change in frequency of moderate PA and country regarding mental HRQoL, no statistically significant interaction was found. All $P$-values of the interaction analyses are presented in Additional file 1: Table A1. 
Finally, sensitivity analyses were performed where all analyses were repeated using the participants in the control group only; we found comparable results (Additional file 1: Table A2 and Table A3).

All analyses were performed with SPSS version 23.0 (IBM SPSS Statistics for Windows, Armonk, NY: IBM Corp). The level of significance was set at $P$-value $<0.05$.

\section{Results}

\section{Baseline characteristics of participants}

The general characteristics of the study population at baseline are presented in Table 1 . The participants' average age was $79.8(\mathrm{SD}=5.2)$ years old, with a range of 70 to 98 years, and $61.0 \%$ of them were female. Participants who engaged in moderated PA with a low frequency at baseline were older $(P<.001)$, were more often female $(P<.001)$, had less often completed tertiary level education $(P<.001)$, were less often at risk for alcohol use $(P<.001)$, more often suffered from multi-morbidity $(P=0.005)$, and were more often frail $(P<.001)$ than those with a regular frequency at baseline.

The frequency of moderate PA of participants at baseline and follow-up as well as change in frequency of moderate PA are presented in Fig. 1. At baseline, 1171 participants reported engaging in moderate PA with a regular frequency. After 12-month follow-up, 947 of these participants (58.7\% of the study population) continued this regular frequency, while 224 of these participants $(13.9 \%)$ had decreased to low frequency. At baseline, 443 participants reported engaging in moderate PA with a low frequency. Of these, 290 (18.0\%) continued this low frequency after 12 months of follow-up, while 153 (9.5\%) had increased to regular frequency.

\section{HRQoL at baseline and follow-up}

The univariate analyses of physical and mental HRQoL at baseline and follow-up by 1) frequency of moderate PA at baseline, and 2) 12-month change in frequency of moderate PA are presented in Table 2 and Fig. 2.

Participants who engaged in moderate PA with a low frequency had significantly poorer physical $(P<.001$; Fig. 2 , Part A) and mental $(P<.001$; Fig. 2 , Part B) HRQoL at follow-up than those who engaged in moderate PA with a regular frequency at baseline. A large difference in physical $(\mathrm{d}=0.91)$ HRQoL and a moderate difference $(d=0.58)$ in mental HRQoL at follow-up were observed.

Part C and D of Fig. 2 show that participants who engaged in moderate PA with a continued regular frequency had the best physical and mental HRQoL among the four categories, while those with a continued low frequency had the poorest physical and mental HRQoL. Participants who decreased their frequency of moderate PA from regular to low had poorer physical $(P<.001$; Fig. 2, Part $C)$ and mental $(P<.001$; Fig. 2, Part D)
HRQoL at follow-up than at baseline. Conversely, participants who increased their frequency of moderate PA from low to regular had better physical $(P=0.011$; Fig. 2, Part $C)$ and mental $(P=0.045$; Fig. 2, Part D) HRQoL at follow-up than at baseline.

Regarding physical HRQoL, a small difference $(\mathrm{d}=$ $0.49)$ at baseline and a moderate difference $(d=0.72)$ at follow-up between participants who engaged in moderate PA with a continued regular frequency and those who decreased their frequency of moderate PA from regular to low were observed. Conversely, a moderate difference $(\mathrm{d}=0.70)$ at baseline and a small difference $(d=0.46)$ at follow-up between participants with a continued regular frequency and those who increased their frequency of moderate PA from low to regular were observed.

Regarding mental HRQoL, a small difference $(\mathrm{d}=0.32)$ at baseline and a moderate difference $(\mathrm{d}=0.61)$ at follow-up between participants who engaged in moderate PA with a continued regular frequency and those who decreased their frequency of moderate PA from regular to low were observed. While, small differences at baseline $(d=0.41)$ and follow-up $(d=0.24)$ between participants with a continued regular frequency and those who increased their frequency of moderate PA from low to regular were observed.

\section{Association between frequency of moderate PA and HRQoL}

The associations between the baseline frequency of moderate PA and the follow-up physical and mental HRQoL according to the multivariate linear regression models are presented in Table 3. After adjusting for the HRQoL at baseline and all the covariates, participants who engaged in moderate PA with a low frequency at baseline had significantly poorer physical $(B=-1.99$; $P<.001)$ and mental $(\mathrm{B}=-1.64 ; P<.01)$ HRQoL at follow-up than those with a regular frequency at baseline.

\section{Association between 12-month change in frequency of moderate PA and HRQoL}

The associations between 12-month change in frequency of moderate PA and physical and mental HRQoL at follow-up according to the multivariate linear regression models are presented in Table 4. A decrease in the frequency of moderate PA or a continued low frequency were significantly correlated with poorer physical and mental HRQoL at follow-up.

After adjusting for physical HRQoL at baseline and all the covariates, participants who decreased their frequency of moderate PA from regular to low $(B=-4.42$; $P<.001)$ and participants who continued the low frequency $(\mathrm{B}=-5.45 ; \quad P<.001)$ had significantly poorer 
Table 1 Baseline characteristics of participants in the analyses $(n=1614)$

\begin{tabular}{|c|c|c|c|c|c|c|c|c|c|}
\hline \multirow[t]{2}{*}{ Characteristics } & \multirow{2}{*}{$\begin{array}{l}\text { Total } \\
(n=1614)\end{array}$} & \multicolumn{3}{|c|}{ Baseline frequency of moderate physical activity } & \multicolumn{5}{|c|}{ 12-month change in physical activity } \\
\hline & & $\begin{array}{l}\text { Regular frequency } \\
(n=1171)\end{array}$ & $\begin{array}{l}\text { Low frequency } \\
(n=443)\end{array}$ & $\begin{array}{l}P \text { - } \\
\text { value }\end{array}$ & $\begin{array}{l}\text { Continued regular } \\
\text { frequency } \\
(n=947)\end{array}$ & $\begin{array}{l}\text { Continued low } \\
\text { frequency } \\
(n=290)\end{array}$ & $\begin{array}{l}\text { Increased } \\
\text { frequency } \\
(n=153)\end{array}$ & $\begin{array}{l}\text { Decreased } \\
\text { frequency } \\
(n=224)\end{array}$ & $\begin{array}{l}P \text { - } \\
\text { value }\end{array}$ \\
\hline$\overline{\text { Age }}$ & $79.8 \pm 5.2$ & $79.3 \pm 4.9$ & $81.2 \pm 5.7$ & $<.001^{\mathrm{a}}$ & $79.0 \pm 4.8$ & $81.9 \pm 5.8$ & $80.0 \pm 5.2$ & $80.5 \pm 5.2$ & $<.001^{b}$ \\
\hline \multicolumn{10}{|l|}{ Gender } \\
\hline Female & $985(61.0)$ & $678(57.9)$ & $307(69.3)$ & $<.001^{\mathrm{C}}$ & $543(57.3)$ & $211(72.8)$ & $96(62.7)$ & $135(60.3)$ & $<.001^{\mathrm{C}}$ \\
\hline Male & $629(39.0)$ & $493(42.1)$ & $136(30.7)$ & & $404(42.7)$ & $79(27.2)$ & $57(37.3)$ & $89(39.7)$ & \\
\hline \multicolumn{10}{|l|}{ Country } \\
\hline Spain & $370(22.9)$ & $306(26.1)$ & $64(14.4)$ & $<.001^{\mathrm{c}}$ & $270(28.5)$ & $24(8.3)$ & $40(26.1)$ & $36(16.1)$ & $<.001^{\mathrm{C}}$ \\
\hline Greece & $163(10.1)$ & $108(9.2)$ & $55(12.4)$ & & $72(7.6)$ & $40(13.8)$ & $15(9.8)$ & $36(16.1)$ & \\
\hline Croatia & $413(25.6)$ & $250(21.3)$ & $163(36.8)$ & & $183(19.3)$ & $127(43.8)$ & $36(23.5)$ & $67(29.9)$ & \\
\hline the Netherlands & $248(15.4)$ & $187(16.0)$ & $61(13.8)$ & & $152(16.1)$ & $30(10.3)$ & $31(20.3)$ & $35(15.6)$ & \\
\hline $\begin{array}{l}\text { the United } \\
\text { Kingdom }\end{array}$ & $420(26.0)$ & $320(27.3)$ & $100(22.6)$ & & $270(28.5)$ & $69(23.8)$ & $31(20.3)$ & $50(22.3)$ & \\
\hline \multicolumn{10}{|l|}{ Educational level } \\
\hline Primary or less & $388(24.2)$ & $293(25.2)$ & $95(21.5)$ & $<.001^{\mathrm{C}}$ & $239(25.4)$ & $57(19.7)$ & $38(25.2)$ & $54(24.3)$ & $<.001^{\mathrm{C}}$ \\
\hline Secondary & $\begin{array}{l}1065 \\
(66.4)\end{array}$ & $741(63.7)$ & $324(73.5)$ & & $604(64.1)$ & $220(75.9)$ & $104(68.9)$ & $137(61.7)$ & \\
\hline Tertiary & $152(9.5)$ & $130(11.2)$ & $22(5.0)$ & & $99(10.5)$ & $13(4.5)$ & $9(6.0)$ & $31(14.0)$ & \\
\hline \multicolumn{10}{|l|}{ Living situation } \\
\hline Living alone & $622(38.6)$ & 437 (37.4) & $185(42.0)$ & $0.093^{c}$ & $352(37.2)$ & $126(43.4)$ & $59(39.1)$ & $85(38.1)$ & $0.298^{c}$ \\
\hline $\begin{array}{l}\text { Living with } \\
\text { others }\end{array}$ & $988(61.4)$ & 732 (62.6) & $256(58.0)$ & & $594(62.8)$ & 164 (56.6) & $92(60.9)$ & $138(61.9)$ & \\
\hline \multicolumn{10}{|l|}{ Smoking } \\
\hline Yes & $118(7.3)$ & $94(8.0)$ & $24(5.4)$ & $0.075^{c}$ & $72(7.6)$ & $14(4.9)$ & $10(6.5)$ & $22(9.8)$ & $0.180^{c}$ \\
\hline No & $\begin{array}{l}1493 \\
(92.7)\end{array}$ & $1076(92.0)$ & $417(94.6)$ & & $874(92.4)$ & $274(95.1)$ & $143(93.5)$ & $202(90.2)$ & \\
\hline \multicolumn{10}{|l|}{ Alcohol risk } \\
\hline Yes & $410(26.6)$ & $339(30.6)$ & $71(16.4)$ & $<.001^{\mathrm{c}}$ & $280(31.1)$ & $36(12.7)$ & $35(23.6)$ & $59(28.4)$ & $<.001^{\mathrm{C}}$ \\
\hline No & $\begin{array}{l}1131 \\
(73.4)\end{array}$ & $770(69.4)$ & $361(83.6)$ & & $621(68.9)$ & $248(87.3)$ & $113(76.4)$ & 149 (71.6) & \\
\hline \multicolumn{10}{|l|}{ Multi-morbidity } \\
\hline Yes & $\begin{array}{l}1460 \\
(90.5)\end{array}$ & $1045(89.3)$ & $415(93.7)$ & $0.008^{\mathrm{c}}$ & $840(88.7)$ & $278(95.9)$ & $137(89.5)$ & $205(91.9)$ & $0.003^{c}$ \\
\hline No & $153(9.5)$ & $125(10.7)$ & $28(6.3)$ & & $107(11.3)$ & $12(4.1)$ & $16(10.5)$ & $18(8.1)$ & \\
\hline \multicolumn{10}{|l|}{ Frailty } \\
\hline Yes & $865(53.8)$ & $523(44.8)$ & $342(77.6)$ & $<.001^{\mathrm{C}}$ & $393(41.7)$ & $240(83.3)$ & $102(66.7)$ & $130(58.0)$ & $<.001^{\mathrm{C}}$ \\
\hline No & $743(46.2)$ & $644(55.2)$ & $99(22.4)$ & & $550(58.3)$ & $48(16.7)$ & $51(33.3)$ & $94(42.0)$ & \\
\hline \multicolumn{10}{|c|}{ Intervention condition } \\
\hline $\begin{array}{l}\text { Yes (intervention } \\
\text { group) }\end{array}$ & $864(53.5)$ & $649(55.4)$ & $215(48.5)$ & $0.013^{c}$ & $524(55.3)$ & $127(43.8)$ & $88(57.5)$ & $125(55.8)$ & $0.003^{c}$ \\
\hline $\begin{array}{l}\text { No (control } \\
\text { group) }\end{array}$ & $750(46.5)$ & $522(44.6)$ & $228(51.5)$ & & $423(44.7)$ & $163(56.2)$ & $65(42.5)$ & $99(44.2)$ & \\
\hline
\end{tabular}

Note: Presented as mean \pm SD or N(\%)

Missing items: Education $=9$; Live situation $=4 ;$ Smoke $=3$; Alcohol $=73 ;$ Frailty $=6$; Multi-morbidity $=1$.

a Independent $\mathrm{T}$ test, significant $P$-values in bold

${ }^{b}$ One-way analysis of variance (ANOVA), significant $P$-values in bold

c Chi-square tests, significant $P$-values in bold

physical HRQoL at follow-up than those with a continued regular frequency. Similarly, after adjusting for mental HRQoL at baseline and all the covariates, participants who decreased their frequency of moderate PA from regular to low $(\mathrm{B}=-3.95 ; P<.001)$ and participants who continued the low frequency $(B=-4.10 ; P<.001)$ had significantly poorer mental HRQoL than those with a continued regular frequency. Furthermore, there was no 


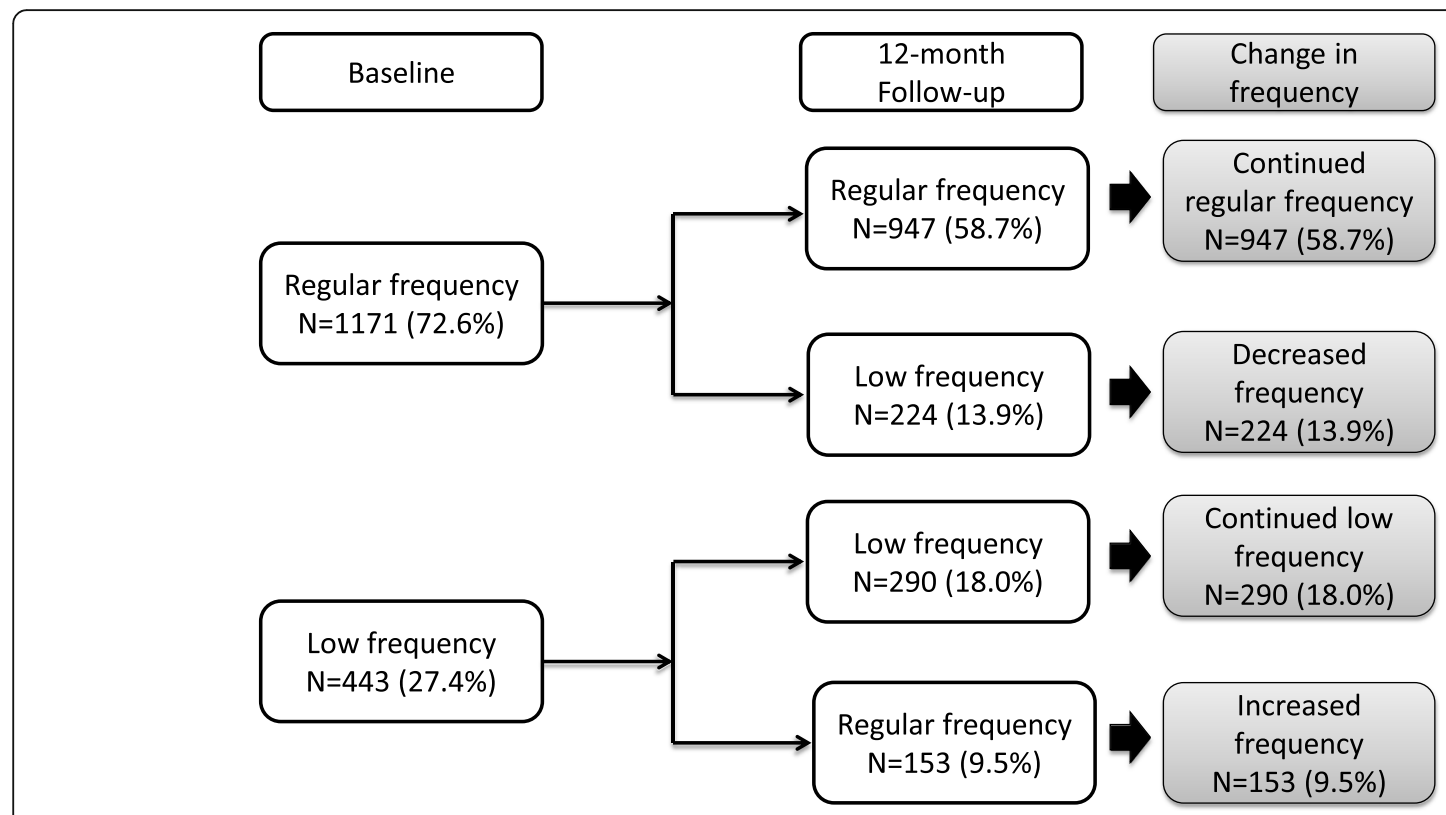

Fig. 1 Frequency of moderate physical activity of participants

significant difference in physical and mental HRQoL at follow-up between participants who increased their frequency from low to regular and participants who continued a regular frequency.

\section{Discussion}

The results of the present study showed that the frequency of moderate PA at baseline is positively associated with HRQoL at follow-up among communitydwelling older adults aged over 70; not only physical but also mental HRQoL. Furthermore, physical and mental HRQoL of participants who engaged in moderate PA with a continued regular frequency were relatively high at both baseline and follow-up. Participants who increased the frequency of moderate PA from low to regular had better physical and mental HRQoL at follow-up than themselves at baseline. After controlling for all covariates and baseline HRQoL, the follow-up physical and mental HRQoL of participants who increased their frequency from low to regular were similar to those who continued a regular frequency. These findings from both univariate analyses and multivariate linear regression models indicate that maintaining a regular frequency of PA as well as a pattern of increasing frequency of PA are associated with maintaining or improving physical and mental HRQoL among community-dwelling older adults aged over 70 .

Some previous studies were in accordance with our findings. A 12-month cohort study conducted in Japan among older adults found that habitual PA, the daily step count and the daily duration of physical activity at an intensity $>3$ metabolic equivalents (METs), was positively associated with both physical and mental domains of HRQoL [8]. An intervention study conducted in Iceland among older adults reported that a 12-week resistance exercise program significantly improved physical function and overall HRQoL [9]. A randomized controlled trial (RCT) conducted in the US among older adults found that PA interventions, walking plus strength and flexibility exercises, can slow the decline in overall HRQoL [27]. One potential explanation of these associations might be that PA may promote physical independence by improving functional capacity and physical health, which are positive changes in life [2]. These changes may have a positive influence on physical HRQoL. Moreover, some previous studies also observed positive effects of exercise on mental health and cognitive performance in adult populations, $[28,29]$ which might be a potential mechanism of the positive association between PA and mental HRQoL.

However, some studies reported different findings compared to our results. A 3-year cohort study conducted in France among adults reported no significant change in physical HRQoL with the change in leisuretime PA (h/week) [30]. A RCT conducted in Ghana among adults with type 2 diabetes reported no significant effects of an 8-week aerobic exercise training on overall HRQoL compared with usual care [11]. The differences might be caused by different study populations, study design and characteristics of PA intervention methods (e.g. the intensity, frequency, and duration of PA). More longitudinal and intervention studies are needed to investigate the optimum PA level to promote HRQoL for specific populations. 
Table 2 Baseline and follow-up mean scores of physical and mental health related quality of life of different physical activity groups

\begin{tabular}{|c|c|c|c|c|c|c|}
\hline \multirow[t]{2}{*}{ Frequency of PA } & \multicolumn{3}{|c|}{ Mean score of physical HRQoL (PCS) } & \multicolumn{3}{|c|}{ Mean score of mental HRQoL (MCS) } \\
\hline & Baseline & Follow-up & $P$-value ${ }^{a}$ & Baseline & Follow-up & $P$-value ${ }^{a}$ \\
\hline \multicolumn{7}{|l|}{ Baseline frequency of PA } \\
\hline Regular frequency $(n=1171)$ & $45.02 \pm 10.33$ & $43.86 \pm 11.03$ & $<.001^{\mathrm{a}}$ & $52.23 \pm 9.33$ & $51.61 \pm 10.17$ & $0.032^{\mathrm{a}}$ \\
\hline Low frequency $(n=443)$ & $33.89 \pm 12.12$ & $33.89 \pm 11.00$ & $0.995^{\mathrm{a}}$ & $45.44 \pm 12.10$ & $44.92 \pm 12.91$ & $0.309^{\mathrm{a}}$ \\
\hline$P$-value ${ }^{b}$ & $<.001^{\mathrm{b}}$ & $<.001^{\mathrm{b}}$ & & $<.001^{\mathrm{b}}$ & $<.001^{b}$ & \\
\hline Effect size ${ }^{c, d}$ & 0.99 & 0.91 & & 0.63 & 0.58 & \\
\hline \multicolumn{7}{|l|}{ Change in PA } \\
\hline Continued regular frequency $(n=947)$ & $46.04 \pm 9.67$ & $45.34 \pm 10.47$ & $0.013^{a}$ & $52.81 \pm 8.98$ & $52.85 \pm 9.42$ & $0.899^{a}$ \\
\hline Continued low frequency $(n=290)$ & $31.48 \pm 11.52$ & $30.41 \pm 9.56$ & $0.044^{\mathrm{a}}$ & $43.75 \pm 12.32$ & $41.95 \pm 13.33$ & $0.003^{\mathrm{a}}$ \\
\hline Increased frequency $(n=153)$ & $38.46 \pm 11.95$ & $40.48 \pm 10.55$ & $0.011^{\mathrm{a}}$ & $48.66 \pm 11.02$ & $50.54 \pm 9.91$ & $0.045^{\mathrm{a}}$ \\
\hline Decreased frequency $(n=224)$ & $40.71 \pm 11.81$ & $37.58 \pm 11.18$ & $<.001^{\mathrm{a}}$ & $49.75 \pm 10.34$ & $46.38 \pm 11.52$ & $<.001^{\mathrm{a}}$ \\
\hline$P$-value ${ }^{\mathrm{e}}$ & $<.001^{c}$ & $<.001^{c}$ & & $<.001^{c}$ & $<.001^{c}$ & \\
\hline Effect size $^{c, f}$ & 1.37 & 1.49 & & 0.84 & 0.94 & \\
\hline Effect size $c, g$ & 0.70 & 0.46 & & 0.41 & 0.24 & \\
\hline Effect size ${ }^{c, h}$ & 0.49 & 0.72 & & 0.32 & 0.61 & \\
\hline
\end{tabular}

Note: Presented as mean \pm SD or N(\%); Regular frequency = more than once a week; Low frequency = once a week or less; Increased frequency = from low to regular frequency; Decreased frequency $=$ from regular to low frequency

Abbreviations: $\mathrm{PA}=$ physical activity; $\mathrm{HRQoL}=$ health-related quality of life; $\mathrm{PCS}=$ physical component summary; $\mathrm{MCS}=$ mental component summary

${ }^{a}$ Paired $T$ test of baseline and follow-up scores, significant $P$-values in bold

b Independent T test of two Baseline frequency of PA groups, significant $P$-values in bold

' Cohen's effect sizes (d) were used for the interpretation of relevant differences: $0.20 \leq d<0.50$ was considered a small difference; $0.50 \leq d<0.80$ was considered

a moderate difference; $d \geq 0.80$ was considered a large difference

d Cohen's effect sizes (d) for differences in HRQoL between Regular frequency of baseline physical activity and Low frequency of baseline physical activity groups

e One-way analysis of variance (ANOVA) of four Change in PA groups, significant $P$-values in bold

${ }^{f}$ Cohen's effect sizes (d) for differences in HRQoL between Continued regular frequency of physical activity and Continued low frequency of physical activity groups

${ }^{g}$ Cohen's effect sizes (d) for differences in HRQoL between Continued regular frequency of physical activity and Increased frequency of physical activity groups

${ }^{\mathrm{h}}$ Cohen's effect sizes (d) for differences in HRQoL between Continued regular frequency of physical activity and Decreased frequency of physical activity groups

Finally, regarding mental HRQoL, we observed an interaction between the 12-month change in frequency of moderate PA and country; in the Netherlands the results were different from the results from the other four countries (see Additional file 1: Table A4). More studies are needed to clarify this finding.

\section{Strengths and limitations}

The addition of empirical data regarding the relationship between change in PA and HRQoL among people aged over 70 years from a representative community-based survey in five European countries is a strength of our research. Furthermore, we applied the SF-12 to measure HRQoL, which has been validated in European countries including the UK, Greece, Croatia, The Netherlands and Spain, [31] to measure physical and mental HRQoL.

However, results of the current study should be interpreted in light of some limitations. First, PA was assessed using a single self-reported question that did not distinguish between types of activities or consider activity duration. We suggest future studies using a more rigorous measurement of $\mathrm{PA}$, for example, the International Physical Activity Questionnaire, [32] to confirm our findings. Second, our analysis included participants in both the intervention and control groups. It's possible that the intervention improved people's health and lead to an overestimation of the impact of PA on HRQoL. However, we adjusted for the intervention condition by adding it as a covariate in the regression models. We also ran the analyses again for the control group only and found comparable results (See Additional file 1: Table A2 and Table A3). Third, participants who were relatively healthy may have participated in the research possibly causing selection bias. Fourth, our observational study cannot prove that PA and HRQoL are causally related. External causes such as an accident, stroke, fall, or other detrimental life circumstances during the year may also have contributed to a decline in PA. Adjusting for multi-morbidity and frailty at baseline only partially illustrates the changes in PA over the 12-month span. Additionally, there might be an overestimation of the association between changes in PA and HRQoL in the regression models since we only controlled for covariates at baseline. Further studies that adopted the study design of multiple repeated measurements, instead of baseline and follow-up only, are recommended to confirm our 


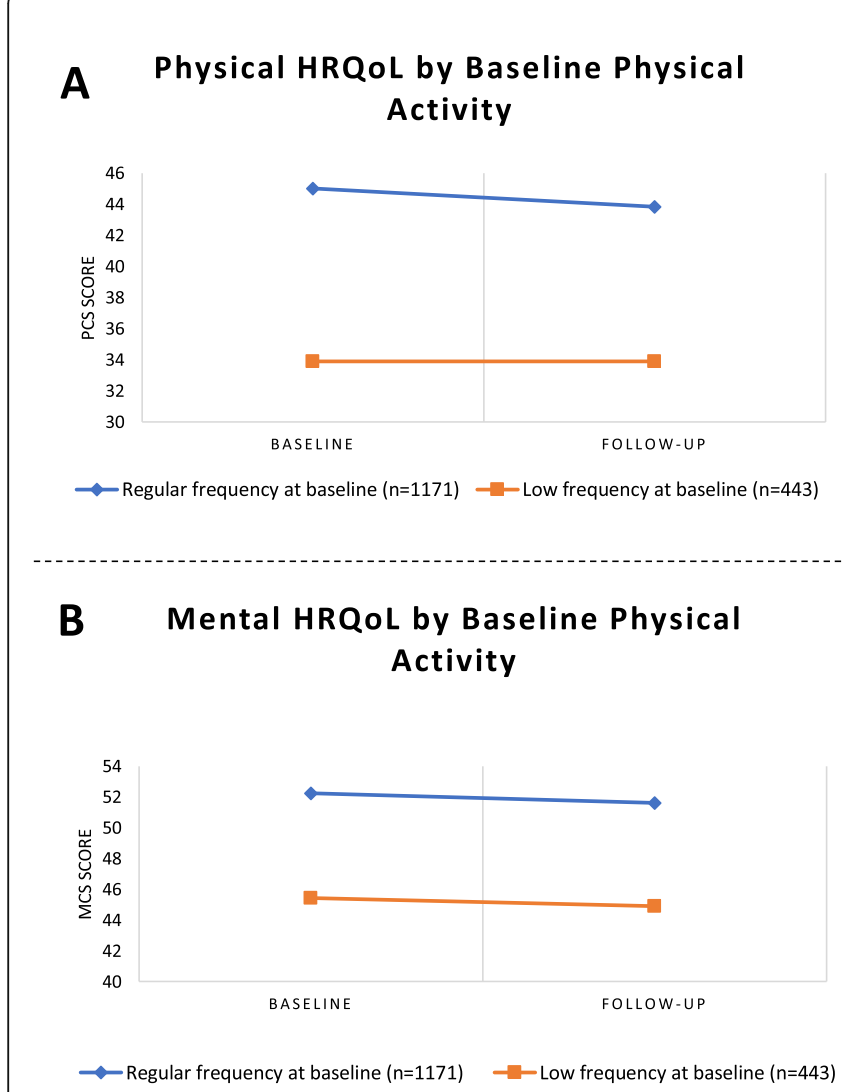

Fig. 2 Health-related quality of life (HRQOL) at baseline and follow-up of participants from the groups of frequency of moderate physical activity: (A) Physical HRQoL by baseline physical activity, (B) Mental HRQoL by baseline physical activity, (C) Physical HRQoL by 12-month change in physical activity, and (D) Mental HRQoL by 12-month change in physical activity

\section{Physical HRQoL by 12-month Change in Physical Activity}

50

45

峞

ชัญ

35

30

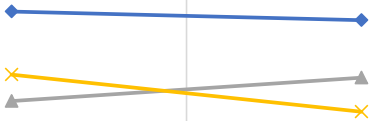

$\longrightarrow-$ Continued regular frequency $(n=947) \quad-\quad-$ Continued low frequency $(n=290)$

- Increased frequency $(n=153) \quad$ Decreased frequency $(n=224)$

\section{Mental HRQoL by 12-month Change in Physical Activity}

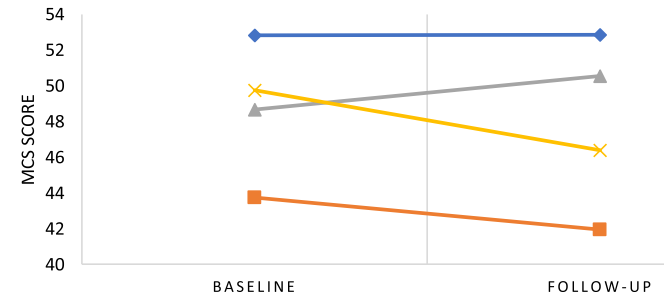

$\multimap$ Continued regular frequency $(n=947) \quad-$ Continued low frequency $(n=290$

$\rightarrow$ Increased frequency $(n=153) \quad \longrightarrow$ Decreased frequency $(n=224)$

Table 3 Multivariate linear regression models (baseline frequency of physical activity and follow-up scores of physical and mental health related quality of life)

\begin{tabular}{|c|c|c|c|c|}
\hline \multirow[t]{2}{*}{$\begin{array}{l}\text { Baseline frequency } \\
\text { of PA }\end{array}$} & \multicolumn{2}{|c|}{$\begin{array}{l}\text { 12-month follow-up } \\
\text { Physical HRQoL score }\end{array}$} & \multicolumn{2}{|c|}{$\begin{array}{l}\text { 12-month follow-up } \\
\text { Mental HRQoL score }\end{array}$} \\
\hline & Crude Model $^{a}$ & Adjusted Model $^{\mathbf{b}}$ & Crude Model $^{c}$ & Adjusted Model $^{\mathrm{d}}$ \\
\hline Regular frequency & Reference & Reference & Reference & Reference \\
\hline Low frequency & $-2.46^{* * *}$ & $-1.99^{* * *}$ & $-2.26^{* * *}$ & $-1.64^{* *}$ \\
\hline Adjusted R square, \% & 50.8 & 53.0 & 43.5 & 44.9 \\
\hline
\end{tabular}

Note: Regular frequency = more than once a week; Low frequency = once a week or less; Increased frequency = from low to regular frequency; Decreased frequency $=$ from regular to low frequency

Abbreviations: $\mathrm{PA}=$ physical activity; $\mathrm{HRQoL}=$ health-related quality of life

${ }^{\text {a }}$ Crude Model: adjusted for country and baseline physical HRQoL score

${ }^{\mathrm{b}}$ Adjusted Model: adjusted for country, baseline physical HRQoL score as well as covariates including age, gender, education level, living situation, smoking, alcohol risk, multi-morbidity, frailty and intervention condition

${ }^{c}$ Crude Model: adjusted for country and baseline mental HRQoL score

d Adjusted Model: adjusted for country, baseline mental HRQoL score as well as covariates including age, gender, education level, living situation, smoking, alcohol risk, multi-morbidity, frailty and intervention condition

${ }^{*} p<.05,{ }^{* *} p<.01,{ }^{* * *} p<.001$, significant effect estimates in bold 
Table 4 Multivariate linear regression models (Change in physical activity and follow-up scores of physical and mental healthrelated quality of life)

\begin{tabular}{|c|c|c|c|c|}
\hline \multirow[t]{2}{*}{ Change in PA } & \multicolumn{2}{|c|}{$\begin{array}{l}\text { 12-month follow-up } \\
\text { Physical HRQoL score }\end{array}$} & \multicolumn{2}{|c|}{$\begin{array}{l}\text { 12-month follow-up } \\
\text { Mental HRQoL score }\end{array}$} \\
\hline & Crude Model $^{a}$ & Adjusted Model $^{\mathbf{b}}$ & Crude Model $^{c}$ & Adjusted Model $^{d}$ \\
\hline Continued regular frequency & Reference & Reference & Reference & Reference \\
\hline Continued low frequency & $-6.01^{* * *}$ & $-5.45^{* * *}$ & $-4.75^{* * *}$ & $-4.10^{* * *}$ \\
\hline Increased frequency & -0.02 & 0.26 & -0.50 & -0.19 \\
\hline Decreased frequency & $-4.60^{* * *}$ & $-4.42^{* * *}$ & $-4.15^{* * *}$ & $-3.95^{* * *}$ \\
\hline Adjusted R square, \% & 53.7 & 55.6 & 45.6 & 46.7 \\
\hline
\end{tabular}

Note: Regular frequency = more than once a week; Low frequency = once a week or less; Increased frequency = from low to regular frequency; Decreased frequency $=$ from regular to low frequency

Abbreviations: $\mathrm{PA}=$ physical activity; $\mathrm{HRQ} \mathrm{oL}=$ health-related quality of life

${ }^{a}$ Crude Model: adjusted for country and baseline physical HRQoL score

b Adjusted Model: adjusted for country, baseline physical HRQoL score as well as covariates including age, gender, education level, living situation, smoking, alcohol risk, multi-morbidity, frailty and intervention condition

c Crude Model: adjusted for country and baseline mental HRQoL score

d Adjusted Model: adjusted for country, baseline mental HRQoL score as well as covariates including age, gender, education level, living situation, smoking, alcohol risk, multi-morbidity, frailty and intervention condition

${ }^{*} p<.05,{ }^{* *} p<.01,{ }^{* * *} p<.001$, significant effect estimates in bold

findings. Fifth, overadjustment bias could arise since we controlled for a large number of covariates, some of which (such as multimorbidity and frailty) may serve both as a confounder and a mediator. On the other hand, although we tried to capture the most important confounding factors, there could still be residual confounding. Sixth, there may be some overlap between PA and two items in physical functioning domain of the SF12 , which might lead to an overestimation of the relationship. However, when we investigated the relationship between PA and physical HRQoL, the results were comparable after excluding these two items. As a result, we do not anticipate that this limitation has changed our findings. Seventh, there is an interaction effect between country and change in moderate PA on mental HRQoL (Additional file 1: Table A1). We recommend future studies to explore this association and to clarify these findings.

\section{Conclusions}

In conclusion, our findings indicated that both maintaining a regular frequency of PA and increasing activity during a year to a regular frequency of PA are associated with maintaining or improving physical and mental HRQoL among European community-dwelling older adults. Our findings support the development of health promotion and long-term care strategies to encourage older adults to maintain regular frequency of PA to promote their quality of life. More longitudinal and intervention studies on the effect of the frequency and intensity levels of PA on HRQoL are needed to better understand and determine the optimum level of PA to promote HRQoL among older adults.

\section{Abbreviations}

HRQOL: Health-related quality of life; ISCED: International Standard Classification of Education; MCS: Mental Component Summary; PA: Physical activity; PCS: Physical Component Summary; RCT: randomized controlled trial; SF-12: 12-Item Short-Form Health Survey; SHARE-Fl: Frailty Instrument of the Survey of Health, Aging and Retirement in Europe; TFI: Tilburg Frailty Indicator; UHCE: Urban Health Centres Europe

\section{Supplementary Information}

The online version contains supplementary material available at https://doi. org/10.1186/s12877-021-02452-y.

\section{Additional file 1.}

\section{Acknowledgements}

We would like to thank all participating older persons and all organizations and professionals involved in the UHCE project.

\section{Authors' contributions}

Study concept and design: XZ AV HR; Acquisition of data: TA AV GW CF HR; Analysis and interpretation of data: XZ SST CF AV HR; Drafting of the manuscript: XZ SST; Critical revision of the manuscript for important intellectual content: all the co-authors.

Funding

This work was supported by the European Union, Consumers, Health, Agriculture and Food Executive Agency (CHAFEA), third health programme, number 20131201.

\section{Availability of data and materials}

The datasets used and/or analysed during the current study are available from the corresponding author on reasonable request.

\section{Declarations}

\section{Ethics approval and consent to participate}

Ethics committee procedures were followed in all cities and institutions involved, and approval was obtained. The names of the review board and the approval references are: Manchester, United Kingdom: NRES Committee West Midlands - Coventry \& Warwickshire; 06-03-2015; 15/WM/0080; NRES Committee South Central - Berkshire B; 29-20-2014; 14/SC/1349; Pallini, Greece: The Ethics and Scientific board - Latriko Palaiou Falirou Hospital; 04/ 03/2015; 20150304-01; Rijeka, Croatia: The Ethical Committee - Faculty of 
Medicine University of Rijeka; 07-04-2014; 2170-24-01-14-02; Rotterdam, The Netherlands: Medische Ethische Toetsings Commissie (METC) - Erasmus MC Rotterdam; 08/01/2015; MEC-2014-661; Valencia, Spain: Comisión de Investigación - Consorcio Hospital General Universitario de Valencia. 29/01/2015; CICHGUV-2015-01-29. All methods were performed in accordance with the relevant guidelines and regulations. Informed consent is obtained from all participants.

\section{Consent for publication}

Not applicable.

\section{Competing interests}

The authors declare that they have no competing interests.

\section{Author details}

'Department of Public Health, Erasmus University Medical Center, P.O. Box 2040, 3000, CA, Rotterdam, The Netherlands. ${ }^{2}$ Center for Healthy Aging and Development Studies, National School of Development, Peking University, Beijing 100871, China. ${ }^{3}$ Polibienestar Research Institute, Universitat de València, 2946022 Valencia, Spain. ${ }^{4}$ Manchester Urban Collaboration on Health, Centre for Epidemiology, Division of Population Health, Health Services Research and Primary Care, Manchester Academic Health Science Centre, The University of Manchester, Manchester, UK.

\section{Received: 12 March 2021 Accepted: 1 September 2021}

\section{Published online: 01 October 2021}

\section{References}

1. The WHOQOL Group. The World Health Organization quality of life assessment (WHOQOL): position paper from the World Health Organization. Soc Sci Med. 1995;41(10):1403-9. https://doi.org/10.1016/0277-953 6(95)00112-K.

2. Vagetti GC, Barbosa Filho VC, Moreira NB, Oliveira V, Mazzardo O, Campos W. Association between physical activity and quality of life in the elderly: a systematic review, 2000-2012. Braz J Psychiatry. 2014;36(1):76-88. https://doi. org/10.1590/1516-4446-2012-0895.

3. Damayanthi H, Moy FM, Abdullah KL, Dharmaratne SD. Health related quality of life and its associated factors among community-dwelling older people in Sri Lanka: a cross-sectional study. Arch Gerontol Geriatr. 2018;76: 215-20. https://doi.org/10.1016/j.archger.2018.03.009.

4. Chai W, Nigg CR, Pagano IS, Motl RW, Horwath C, Dishman RK. Associations of quality of life with physical activity, fruit and vegetable consumption, and physical inactivity in a free living, multiethnic population in Hawaii: a longitudinal study. Int J Behav Nutr Phys Act. 2010;7(1):83. https://doi.org/1 0.1186/1479-5868-7-83.

5. Anokye NK, Trueman P, Green C, Pavey TG, Taylor RS. Physical activity and health related quality of life. BMC Public Health. 2012;12(1):624. https://doi. org/10.1186/1471-2458-12-624.

6. Bize R, Johnson JA, Plotnikoff RC. Physical activity level and health-related quality of life in the general adult population: a systematic review. Prev Med. 2007:45(6):401-15. https://doi.org/10.1016/j.ypmed.2007.07.017.

7. Thiel DM, AI Sayah F, Vallance JK, Johnson ST, Johnson JA. Association between physical activity and health-related quality of life in adults with type 2 diabetes. Can J Diabetes. 2017;41(1):58-63. https://doi.org/10.1016/j. jcjd.2016.07.004.

8. Aoyagi Y, Park H, Park S, Shephard RJ. Habitual physical activity and healthrelated quality of life in older adults: interactions between the amount and intensity of activity (the Nakanojo study). Qual Life Res : Int J Qual Life Aspects Treatment, Care and Rehab. 2010;19(3):333-8. https://doi.org/10.1 007/s11136-010-9588-6.

9. Geirsdottir OG, Arnarson A, Briem K, Ramel A, Tomasson K, Jonsson PV, et al. Physical function predicts improvement in quality of life in elderly Icelanders after 12 weeks of resistance exercise. J Nutr Health Aging. 2012; 16(1):62-6. https://doi.org/10.1007/s12603-011-0076-7.

10. van der Heijden MM, van Dooren FE, Pop VJ, Pouwer F. Effects of exercise training on quality of life, symptoms of depression, symptoms of anxiety and emotional well-being in type 2 diabetes mellitus: a systematic review. Diabetologia. 2013;56(6):1210-25. https://doi.org/10.1007/s00125-013-2871-7.

11. Bello Al, Owusu-Boakye E, Adegoke BO, Adjei DN. Effects of aerobic exercise on selected physiological parameters and quality of life in patients with type 2 diabetes mellitus. Int J Gen Med. 2011;4:723-7. https://doi.org/10.214 7/IJGM.S16717.

12. Wendel-Vos GC, Schuit AJ, Tijhuis MA, Kromhout D. Leisure time physical activity and health-related quality of life: cross-sectional and longitudinal associations. Qual Life Res. 2004;13(3):667-77. https://doi.org/10.1023/B: QURE.0000021313.51397.33.

13. Franse $C B$, van Grieken A, Alhambra-Borrás T, Valía-Cotanda E, van Staveren $R$, Rentoumis $T$, et al. The effectiveness of a coordinated preventive care approach for healthy ageing (UHCE) among older persons in five European cities: a pre-post controlled trial. Int J Nurs Stud. 2018;88:153-62. https://doi. org/10.1016/j.jijnurstu.2018.09.006.

14. Franse CB, Voorham AJJ, van Staveren R, Koppelaar E, Martijn R, Valía-

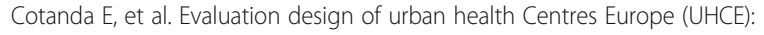
preventive integrated health and social care for community-dwelling older persons in five European cities. BMC Geriatr. 2017;17(1):209. https://doi.org/1 0.1186/s12877-017-0606-1.

15. Franse $C B$, Zhang $X$, van Grieken A, Rietjens J, Alhambra-Borrás T, Durá E, et al. A coordinated preventive care approach for healthy ageing in five European cities: A mixed methods study of process evaluation components. 2019;75(12):3689-701. https://doi.org/10.1111/jan.14181.

16. Zhang $X$, Tan SS, Franse CB, Bilajac L, Alhambra-Borrás T, Garcés-Ferrer J, et al. Longitudinal association between physical activity and frailty among community-dwelling older adults. J Am Geriatr Soc. 2020;68(7):1484-93. https://doi.org/10.1111/jgs.16391.

17. Ware J, Kosinski M, Keller SD. A 12-item short-form health survey: construction of scales and preliminary tests of reliability and validity. Med Care. 1996;34(3):220-33. https://doi.org/10.1097/00005650-199603000-00003.

18. Provencher V, Sirois M-J, Émond M, Perry JJ, Daoust R, Lee JS, et al. Frail older adults with minor fractures show lower health-related quality of life (SF-12) scores up to six months following emergency department discharge. Health Qual Life Outcomes. 2016;14(1):40. https://doi.org/10.1186/ s12955-016-0441-7.

19. Díaz-Arribas MJ, Fernández-Serrano M, Royuela A, Kovacs FM, GallegoIzquierdo T, Ramos-Sánchez M, et al. Minimal clinically important difference in quality of life for patients with low Back pain. Spine. 2017;42(24):1908-16. https://doi.org/10.1097/BRS.0000000000002298.

20. Schneider Silke L: The International Standard Classification of Education 2011. In: Class and Stratification Analysis. Edited by Gunn Elisabeth B, vol. 30: Emerald Group Publishing Limited; 2013: 365-379.

21. Bush K, Kivlahan DR, McDonell MB, Fihn SD, Bradley KA. The AUDIT alcohol consumption questions (AUDIT-C): an effective brief screening test for problem drinking. Ambulatory care quality improvement project (ACQUIP). Alcohol use disorders identification test. Arch Intern Med. 1998;158(16): 1789-95. https://doi.org/10.1001/archinte.158.16.1789.

22. Gobbens RJ, Schols JM, van Assen MA. Exploring the efficiency of the Tilburg frailty Indicator: a review. Clin Interv Aging. 2017;12:1739-52. https:// doi.org/10.2147/CIA.S130686

23. Gobbens RJJ, van Assen MALM, Luijkx KG, Wijnen-Sponselee MT, Schols JMGA. The Tilburg frailty Indicator: psychometric properties. J Am Med Dir Assoc. 2010;11(5):344-55. https://doi.org/10.1016/j.jamda.2009.11.003.

24. Quah JHM, Wang P, Ng RRG, Luo N, Tan NC. Health-related quality of life of older Asian patients with multimorbidity in primary care in a developed nation. Geriatr Gerontol Int. 2017;17(10):1429-37. https:/doi.org/10.1111/ggi.12881.

25. Börsch-Supan A: Survey of Health, Ageing and Retirement in Europe (SHARE) Wave 5. Release version: 710 SHARE-ERIC 2019.

26. Cohen J: Statistical power analysis for the behavioral sciences: academic press; 2013, https://doi.org/10.4324/9780203771587.

27. Groessl EJ, Kaplan RM, Rejeski WJ, Katula JA, Glynn NW, King AC, et al. Physical activity and performance impact long-term quality of life in older adults at risk for major mobility disability. Am J Prev Med. 2019;56(1):141-6. https://doi.org/10.1016/j.amepre.2018.09.006.

28. Halloway S, Wilbur J, Schoeny ME, Arfanakis K. Effects of endurance-focused physical activity interventions on brain health: a systematic review. Biol Res Nurs. 2017;19(1):53-64. https://doi.org/10.1177/1099800416660758.

29. Kirk-Sanchez NJ, McGough EL. Physical exercise and cognitive performance in the elderly: current perspectives. Clin Interv Aging. 2014;9:51-62. https:// doi.org/10.2147/CIA.S39506.

30. Tessier S, Vuillemin A, Bertrais S, Boini S, Le Bihan E, Oppert JM, et al. Association between leisure-time physical activity and health-related quality of life changes over time. Prev Med. 2007;44(3):202-8. https://doi.org/10.101 6/j.ypmed.2006.11.012. 
31. De Smedt D, Clays E, Doyle F, Kotseva K, Prugger C, Pająk A, et al. Validity and reliability of three commonly used quality of life measures in a large European population of coronary heart disease patients. Int J Cardiol. 2013; 167(5):2294-9. https://doi.org/10.1016/j.jicard.2012.06.025.

32. Cleland C, Ferguson S, Ellis G, Hunter RF. Validity of the international physical activity questionnaire (IPAQ) for assessing moderate-to-vigorous physical activity and sedentary behaviour of older adults in the United Kingdom. BMC Med Res Methodol. 2018;18(1):176. https://doi.org/10.1186/ s12874-018-0642-3.

\section{Publisher's Note}

Springer Nature remains neutral with regard to jurisdictional claims in published maps and institutional affiliations.

Ready to submit your research? Choose BMC and benefit from:

- fast, convenient online submission

- thorough peer review by experienced researchers in your field

- rapid publication on acceptance

- support for research data, including large and complex data types

- gold Open Access which fosters wider collaboration and increased citations

- maximum visibility for your research: over $100 \mathrm{M}$ website views per year

At $\mathrm{BMC}$, research is always in progress.

Learn more biomedcentral.com/submissions 